Revista Eletrônica do Mestrado em Educação Ambiental

Programa de Pós-Graduação em Educação Ambienta1

\title{
Discursos Esverdeantes e atravessamentos com a Ecopolítica
}

\author{
Isabel Ribeiro Marques ${ }^{1}$ \\ Universidade Federal do Rio Grande \\ http://orcid.org/0000-0002-2179-5899 \\ Paula Correa Henning ${ }^{2}$ \\ Universidade Federal do Rio Grande \\ http://orcid.org/0000-0003-3697-9030
}

Resumo: O presente trabalho provém de uma tese do Programa de Pós Graduação em Educação Ambiental na Universidade Federal do Rio Grande que, em vias de finalização, analisa os Discursos Esverdeantes pulverizados por diferentes mídias e problematiza tais discursos fortemente relacionados ao verde, sendo muitas vezes vinculados a ideais de verdade e conduzindo a comportamentos diante das mazelas ambientais da contemporaneidade. Através das recorrências que o material da tese apresentou destacamos o conceito de ecopolítica para pensarmos sobre as imagens relacionadas ao planeta aliadas ao signo "eco", entrelaçando sobre as estratégias biopolíticas que convergem para que esses discursos se tornem tão potentes e convincentes.

Palavras-chave: Educação Ambiental; Michel Foucault; ecopolítica.

\section{Discursos ecológicos y entrelazamientos con la ecopolítica}

Resumen: El presente trabajo proviene de una tesis del Programa de Posgrado en Educación Ambiental de la Universidad Federal de Río Grande-RS, Brasil, que, en las etapas finales, analiza los "Discursos Esverdeantes" pulverizados por diferentes medios y problematiza estos discursos fuertemente relacionados con el verde, vinculados a ideales de verdad y conductas orientadoras frente a los males ambientales contemporáneos. A través de las recurrencias que presentó el material de tesis, destacamos el concepto de ecopolítica para pensar en las imágenes relacionadas con el planeta aliadas al "eco", entrelazando las estrategias biopolíticas que convergen para hacer que estos discursos sean tan potentes y convincentes.

Palabras clave: educacion ambiental; Michel Foucault; ecopolítica.

\footnotetext{
${ }^{1}$ Doutoranda em Educação Ambiental - FURG; Mestre em Educação e Tecnologia - IFSUL (2015); pós graduada em Direito Ambiental - UFPEL; graduada em Direito (2005) e em Ecologia (2008), ambos pela UCPEL. Docente na UCPEL desde 2011 (atualmente afastada para o doutorado) Bolsista CAPES. e-mail: isabel.marques.82@ gmail.com

2 Pós-Doutora em Filosofia pela Univeridad de Murcia/Espanha (2017 Estágio Sênior Capes). Doutora em Educação pela Universidade do Vale do Rio dos Sinos (2008 Bolsista CAPES). Mestre em Educação pela Universidade Federal de Pelotas (2003 Bolsista CAPES). Graduada em Pedagogia pela Universidade Católica de Pelotas (2000). Bolsista Produtividade 2 do CNPq. e-mail: paula.c.henning@gmail.com
}

Rev. Eletrônica Mestr. Educ. Ambient. Rio Grande. v. 37, n. 1. Seção especial: XI EDEA - Encontro e Diálogos com a Educação Ambiental. p. 228-246. jan/abr. 2020. 


\section{Green Discourses and relationship with Ecopolitics}

Abstract: The present text comes from a thesis of the Postgraduate Program in Environmental Education of the Federal University of Rio Grande that, in the final stages, analyzes the green Discourses pulverized by different means and problematizes these discourses strongly related to the green, linked to ideals of truth and guiding behavior against contemporary environmental evils. Through the recurrences presented by the thesis material, we highlight the concept of ecopolitics to think about the images related to the planet allied to the "eco", intertwining the biopolitical strategies that converge to make these speeches so powerful and convincing.

Keywords: environmental educacion; Michel Foucault; ecopolitics.

\section{Apontamentos iniciais}

"O planeta está em crise". "As mazelas ambientais se aproximam". "Estamos acabando com a capacidade de suporte dos recursos naturais". "Aquecimento global". "Derretimento das geleiras". Alguma surpresa em ler esses enunciados catastróficos em relação ao planeta?

Acreditamos que sua resposta seja: Não!

As mídias reiteram esses discursos a todo momento, a ciência é trazida a reforçar os dados, apontando os números, as porcentagens, as estatísticas que podem conduzir a um calamitoso futuro, caso não estejamos engajados em cuidar, proteger, preservar e salvar nosso planeta.

Esse trabalho provém de uma tese ${ }^{3}$, que tem como cerne a formulação do conceito que foi denominado Discurso Esverdeante (DE) em que, através de um portfólio de imagens coletadas em diferentes mídias, se analisou as principais recorrências que, sob subterfúgio verde, estimulam o consumo de determinados produtos e/ou serviços, conduzindo e educando sobre as maneiras de ser e viver na contemporaneidade.

Além do material enquanto visibilidade e enunciabilidade, o que emergiu nos processos de análise, foi a subjetividade entremeada através das imagens, nos conduzindo rebanhamente em salvar o planeta em busca da possibilidade de um futuro. Pensando sob tais atravessamentos, na presente escrita, destacamos o conceito da Ecopolítica, aonde além das questões atreladas às políticas da vida, presencia-se uma política concernente às maneiras de se lidar com o planeta.

Com o apoio teórico de autores como Michel Foucault, Friedrich Nietzsche e Edison Passeti, buscamos articular algumas imagens do portfólio com a ecopolítica, conceito muito caro para pensar os atravessamentos biopolíticos em um momento onde as

\footnotetext{
3 Tese de autoria da primeira autora sob orientação da segunda autora.
}

Rev. Eletrônica Mestr. Educ. Ambient. Rio Grande. v. 37, n. 1. Seção especial: XI EDEA - Encontro e Diálogos com a Educação Ambiental. p. 228-246. jan/abr. 2020. 
questões relacionadas ao planeta estão com tanta evidência. Almejamos a criação de possibilidade de pensarmos sobre verdades tão consolidadas que alocam o homem tanto como causador do colapso planetário, como aquele que pode salvar o planeta da crise criada por ele próprio

Para tal feito, o trabalho foi dividido em três partes, aqui na primeira tecemos uma introdução ao tema, na segunda parte é apresentada uma contextualização em relação a biopolítica, para que na terceira parte fosse entrelaçado ao conceito da ecopolítica, seguindo das considerações.

\section{Considerações sobre a Biopolítica}

A biopolítica, embora não seja um conceito inaugurado por Foucault, foi visibilizado através de seus textos. A primeira referência do autor em modo público em relação ao tema, data de 1974, onde em uma conferência no Rio de Janeiro comenta:

O controle da sociedade sobre os indivíduos não se opera simplesmente pela consciência ou pela ideologia, mas começa no corpo com corpo (...) o corpo é uma realidade biopolítica. A medicina é uma estratégia biopolítica (FOUCAULT, 2015, p. 80).

Segundo Foucault (2015, p. 404), as políticas endereçadas a vida da população tornaram-se importantes a partir do século XVIII, em primeiro lugar: quando as epidemias, as condições de habitat, de higiene, dentre outros, começam a integrar problemas centrais; em segundo lugar: quando em relação a esses problemas, outros tipos de saber passam a ser implicados, tais como: aparecimento da demografia, observação sobre a repartição de epidemias, inquérito sobre as amas de leite, sobre as condições de aleitamento das crianças; em terceiro lugar, com o estabelecimento de aparelhos de poder que permitem não somente a observação, mas a intervenção direta a tudo isso que se passa. Através das informações da população começa a haver uma série de ações. Nas palavras de Foucault: "Neste momento, começa algo que se pode chamar de poder sobre a vida" (2015, p. 404)

Com o "poder sobre a vida", através das políticas de vida biológica, como "poder sobre a morte", por exemplo, através do racismo, Foucault nomeia como Biopoder a estatização da vida biologicamente considerada, ou seja, do homem enquanto um ser vivente (CASTRO, 2016, p. 57). Biopoder então é entendido como um conjunto de mecanismos que através da constituição das características biológicas da espécie humana entram em uma política, em uma estratégia geral de poder (FOUCAULT, 2008c, p. 3). 
Para que a questão da população e sua arte de governo obtivessem importância foi um longo e paulatino processo. A arte de governar encontra desde o final do século XVI e início do século XVII as primeiras formas de se organizar em torno do tema de uma razão do estado, estado esse que governa não no sentido negativo ou pejorativo, mas segundo as regras que lhe são próprias, não provindo nem de leis naturais ou divinas, tampouco de preceitos de sabedoria ou prudência (FOUCAULT, 2015, p. 420).

Foucault (2015, p. 422) diz que durante o século XVII até o século XVIII a arte do governo foi limitada por duas coisas principais: a soberania, quadro muito vasto e rígido e por outro lado a família, tido como estreito, débil e inconsistente:

\begin{abstract}
A arte de governar procurou fundar-se na forma geral da soberania, ao mesmo tempo que não pôde deixar de apoiar-se no modelo concreto da família; por esse motivo, ela foi bloqueada pela ideia da economia, que nessa época ainda se referia apenas a um pequeno conjunto constituído pela família e pela casa. Com o Estado e o soberano de um lado, com o pai de família e sua casa de outro, a arte de governo não podia encontrar dimensão própria (FOUCAULT, 2015, p. 423).
\end{abstract}

Outra informação importante nessa caminhada em direção à biopolítica e também à ecopolítica é que, seguindo nos escritos de Foucault, a arte de governo foi desbloqueada pelo problema da população, que permitiu eliminar o modelo de família e centralizar a questão da economia em outra coisa (FOUCAULT, 2015, p. 424). O autor comenta que se a estatística tinha funcionado na administração da soberania, revelou pouco a pouco, por sua atividade e modo de agir, que a população tem uma regularidade peculiar (como número de mortos, de doentes, de acidentes) e possui efeitos econômicos específicos. A partir de então a família passa de modelo para instrumentação, ou seja, a ser elemento interior a população e como um apoio ao governo desta (FOUCAULT, 2008c, p. 139).

Esse desbloqueio da arte de governar tem importância direta com a questão da biopolítica, pois ao eliminar o modelo de família, quando a população aparece como um objetivo do governo, precisou-se lançar mão para se alcançar esses fins, eis que as campanhas e dos convencimentos entram em cena (e nos atrevemos a dizer que nunca mais saíram):

[...] é a população considerada do ponto de vista das suas opiniões, das suas maneiras de fazer, dos seus comportamentos, dos seus hábitos, dos seus temores, dos seus preconceitos, das suas exigências, é aquilo sobre o que se age por meio da educação, das campanhas, dos convencimentos (FOUCAULT, 2008c, p. 98-99). 
A população aparecendo mais como um instrumento do que como força do soberano, trata-se de uma movimentação muito salientada por Foucault, onde, através de táticas e novas técnicas, evidencia-se uma passagem de um regime de soberania para um regime de técnicas de governo, da arte de governo para uma ciência política. Com tal deslocamento a economia política passa a configurar a arte de governar, sendo a população alvo e instrumento fundamental:

\begin{abstract}
A população aparece, portanto mais como fim e instrumento do governo que como força do soberano; a população aparece como sujeito de necessidades, de aspirações, mas também como objeto nas mãos do governo; como consciente, ante o governo, daquilo que ela quer e inconsciente em relação àquilo que se quer que faça. $O$ interesse individual - como consciência de cada indivíduo constituinte da população- e o interesse geral - como interesse da população, quaisquer que sejam os interesses e as aspirações individuais daqueles que a compõem - constituem alvo e o instrumento fundamental do governo da população. Nascimento, portanto de uma arte ou, em todo caso, de táticas e técnicas absolutamente novas (FOUCAULT, 2015, p. 426).
\end{abstract}

Assim, a biopolítica se dá através de estratégias de poder, aonde através dessas práticas, há regulação da vida como um todo, desde antes do nascimento, através de programas que visam controlar a natalidade, e pós nascimento também, lidando com muitos dados estatísticos, regulando atividades do cotidiano.

A biopolítica toma a vida como objeto político, tratando-se de uma política que orienta a vida das populações e tem como interesse e preocupação a própria vida da população em termos de governá-la no que se refere a saúde- morbidade e também no que concerne a sua higiene, alimentação, natalidade, mortalidade, sexualidade, longevidade, fecundidade, casamentos etc. (VEIGA-NETO, 2014, p. 36-37). Interessante pensar que as maneiras do poder operar não se dão como uma simples sujeição:

A relação do poder com o indivíduo não deve ser simplesmente uma forma de sujeição que permite ao poder tomar dos sujeitos, bens, riquezas e, eventualmente, seu corpo e seu sangue, mas o poder deve exercer-se sobre os indivíduos os considerando como uma entidade biológica que deve ser levada em consideração, para ser utilizada como máquina de produção de riquezas, bens e também outros indivíduos (FOUCAULT, 2006, p. 193).

Sauquillo (2017, p. 531-532), diz que biopolítica das populações é uma estratégia disposta pelo poder para incrementar a população e acrescentar um rendimento efetivo, através de um controle intensivo e descentralizado sobre a população como um todo, 
através de uma governamentalidade, com uma constante e capilar intervenção sobre os indivíduos. Essas técnicas são muito ligadas a práticas disciplinares, aonde gestos, comportamentos e ações são previamente esperados.

Embora haja a atuação de práticas disciplinares em relação a biopolítica, consideramos interessante comentar que ambas possuem algumas características diferenciadas, muito bem salientadas por Castro (2016), como em relação ao objeto: em que a disciplina atua no corpo individual e a biopolítica no corpo múltiplo, ou seja na população. Quanto aos fenômenos considerados: a disciplina leva em consideração aqueles individuais, enquanto a biopolítica estuda os fenômenos de massa, em série, de longa duração. No que se concerne aos mecanismos: a disciplina tange principalmente ao adestramento do corpo, através de vigilância hierárquica, exames individuais, exercícios repetitivos; no que se refere a biopolítica, esta se dá através de mecanismo de previsão, estatística, medidas globais. Ainda que se complementem, suas finalidades são distintas: a disciplina busca corpos economicamente úteis e politicamente dóceis e a biopolítica persegue o equilíbrio da população e sua regulação.

Uma das marcas da questão biopolítica é a estatística. A vida ganha importância e os cálculos estatísticos informam as taxas e os índices, dessa maneira, a biopolítica entra em cena como uma política que, visando assegurar a vida do homem, lança mão desses dados para ações, regulações e o controle sobre as populações. De acordo com Henning (2019, p. 5), a biopolítica é tomada por Foucault, como uma política que, a partir de cálculos e prognósticos regula a população por meio de ações governamentais, no desejo de assegurar a vida coletiva.

Tais ações governamentais tem a ver com a governamentalidade, outro termo recorrente em se tratando de biopolítica. Conforme Veiga-Neto, essa expressão foi criada por Foucault para designar uma série de questões atinentes à maneiras de governar e as formas nas quais se conduzem às ações, funcionando como uma espécie de dobradiça capaz de articular o que é próprio da população com o que é próprio das subjetividades, ou então articulando o coletivo com o individual, extravasando além da dimensão política e populacional (VEIGA-NETO, 2014, p. 37).

De acordo com Foucault, a governamentalidade pode ser atribuída a três fatores principais: oconjunto constituído pelas instituições, procedimentos, cálculos e táticas, que permitem que o poder exista, tendo por alvo a população, através de dispositivos de segurança e pela economia política; a preeminência de um sistema de poder chamado governo, que se dá em relação aos outros, como a soberania e a disciplina e, por fim, os 
processos de conversão do estado de justiça da idade média, para o estado administrativo (séculos XV e XVI) que pouco a pouco foi governamentalizado (FOUCAULT, 2015, p. 429).

Interessante pensar que ao discutir biopolítica, Foucault não empreendeu o conceito para pensar as questões ambientais, porém diante do governo da vida humana sendo ampliado à um poder sobre à maneira de lidar com o planeta, a ecopolítica emerge como um alargamento da biopolítica, vindo a potencializar às discussões atinentes a seara ambiental.

\section{Deslocamentos da Biopolítica para uma ecopolítica}

Sob fulcro em Foucault que traz a biopolítica como política da vida; sob as constantes atualizações discursivas que contribuem e reforçam as subjetividades; diante da problemática ambiental que atravessa a contemporaneidade; com as imagens distribuídas pelas mídias que reforçam a necessidade de se mudar os hábitos de vida em relação ao planeta; destacamos a Ecopolítica como um potente conceito para pensarmos as questões ambientais, aonde além do poder sobre a vida humana, é presenciado um poder sobre à maneira de lidar com o planeta.

De acordo com Passetti (2013), passamos hoje por um momento em que a biopolítica é cada vez mais ecopolítica, pois, tanto quanto proteger o corpo-máquina (anátomo-política) e o corpo-espécie (biopolítica) é imperativo defender o corpo do planeta, seu equilíbrio, sua biodiversidade, seus ecossistemas, de forma que permitam a permanência do humano. E para isso, é necessário um controle e uma regulamentação que, tanto permitam a sustentabilidade do planeta, quanto não ameacem a estrutura do poder constituído e também das relações financeiras contemporâneas.

Entendemos a ecopolítica como um alargamento da biopolítica, aonde além das estratégias operadas nas relações humanas, nas práticas da vida, há uma política que concerne às maneiras de lidarmos com o planeta. Malette (2011, p. 10) diz que o "conceito de biopolítica é ampliado para incluir tudo o que seja necessário para manter a "vida" pela emergência de diversas práticas e regulações ambientais". Siqueira (2012, p. 42) amplia, dizendo que na presença de investimentos para a órbita do planeta, a ampliação da biopolítica transbordaria para fora do planeta.

Segundo Veiga- Neto (2014, p. 33) a ecopolítica é um novo horizonte para a 
biopolítica, ampliando tudo o que já foi pensado e dito, aonde expande do humano ao planetário o papel conferido à vida. Outro traço pontuado pelo autor e, que convergem ainda mais com o conceito trabalhado para a tese, é o acento ético dos discursos ecopolíticos, aonde há uma defesa candente a favor de novas formas de lidar com o planeta, pontuados principalmente em interesses econômicos aliados aos interesses sociais (p. 9).

Entendemos que esse "acento" que o autor destaca, converge ao Discurso Esverdeante que a tese, que originou a presente escrita, conceitua, estimulando o consumo de produtos e/ou serviços sob subterfúgio verde. Tais Discursos Esverdeantes estão esparramados, as imagens se pulverizam por incontáveis lugares, seja em embalagens de produtos, em revistas, sacolas, redes sociais, dentre tantos meios midiáticos que vão reativando sem cessar tais discursos. Ressaltamos que não se trata de questionar as práticas de produção e/ou funcionamento utilizadas pelas empresas, mas a problematização que propomos é que possamos pensar que esses ditos são tidos com tanta veracidade que muitas vezes não ousamos questioná-los.

O discurso ambiental está em voga. Os ditos catastróficos são constantes. O discurso do medo pelo fim do planeta e que nos ensina a ser e a lidar com a problemática global nos cercam. Nesses atravessamentos, Barchi, ironiza sobre a "necessidade de uma vida ecologicamente correta" tão reiterada:

É necessária uma nova forma de vida política e ecologicamente correta para que o planeta e a humanidade sobrevivam. Mais do que o urso polar, o panda ou a baleia-azul, é preciso salvar o humano. E para isso, deve ocorrer uma reforma ecológica que o faça impedir de destruir a Terra (BARCHI, 2011, p. 8).

Nessa congruidade, do ecologicamente correto, dos Discursos Esverdeantes esparramados, compartilhamos na Figura 1, uma embalagem de café "Aroma e sabor respeitando o planeta", hastes com ponta de algodão "Eco" com a informação "Cuida de você, da sua família e do planeta", a embalagem de suco alerta o cuidado que devemos ter em relação ao planeta "o planeta é gigante, só que a gente tem que cuidar como se ele fosse pequenininho, entendeu?". O mercado ainda oferece "eco canudo", "telha ecológica", produtos para cabelo "Maria natureza" e "madeira ecológica". 
Figura 1: Imagens ressaltando cuidado com o planeta e o signo "eco"

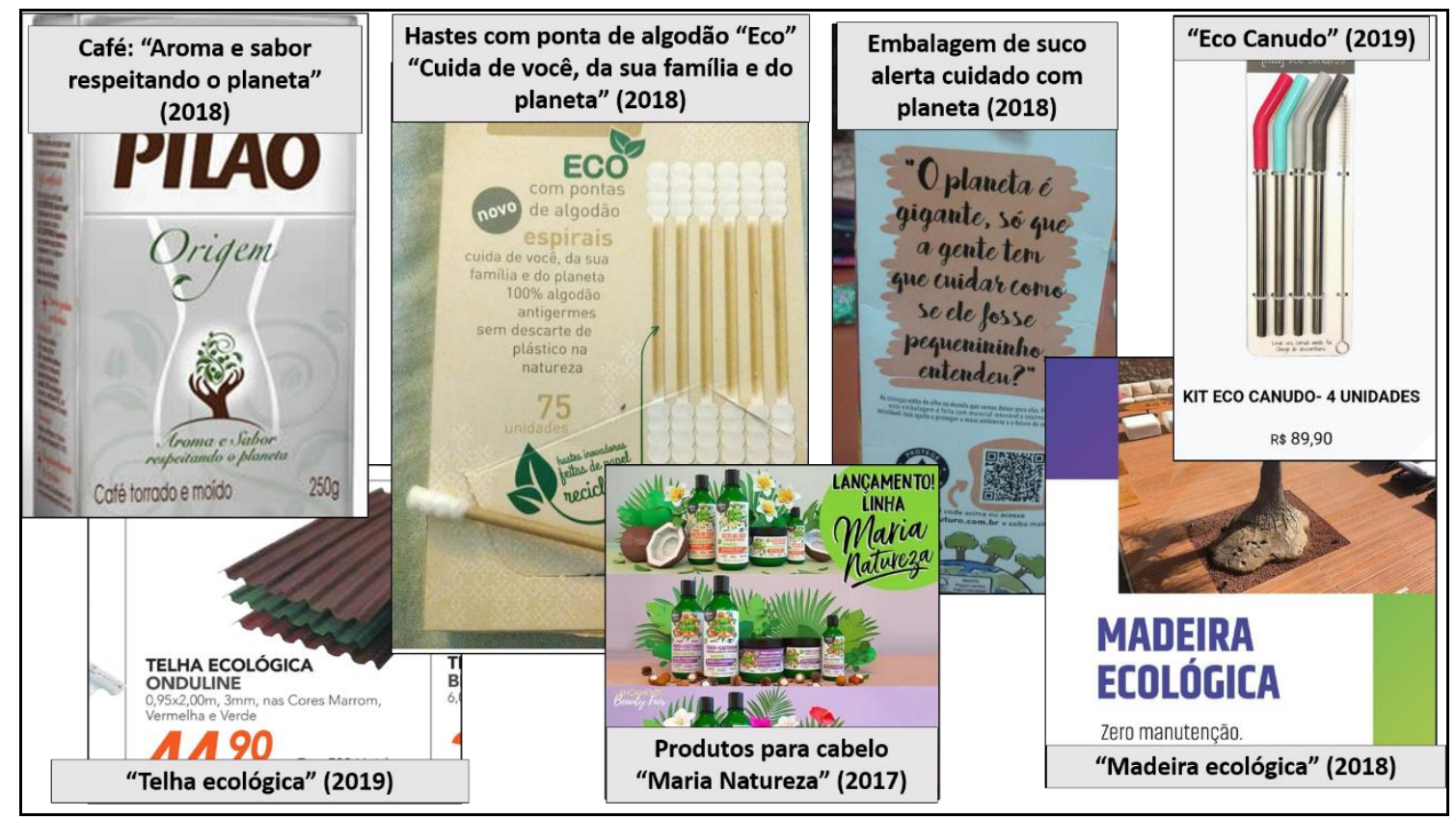

Fonte: Portfólio das imagens coletadas para a tese

Alguns materiais analíticos são citados para estimular que pensemos sobre os constantes atravessamentos que nos constituem cotidianamente e que nos ensinam a lidar com a crise. E, olhando esse material recordamos Foucault ao tratar sobre formas de poder e diz que o poder emerge do cotidiano:

[...] forma de poder emerge em nossa vida cotidiana, categoriza o indivíduo, o marca por sua própria individualidade, une-o a sua própria identidade, lhe impõe uma lei de verdade que ele tem que reconhecer e que ao mesmo tempo, outros devem reconhecer nele. É uma forma de poder que constitui sujeitos individuais (FOUCAULT, 1995, p. 235).

Em consonância com Foucault que trata da governamentalidade, alguns autores destacam que há uma ecogovernamentalidade através de uma "reorganização dos conceitos de população, segurança e economia política, nos quais a regulação dos vivos se expandiria para regulação de tudo o que necessário para a vida" (MALETTE, 2011, p. 4).

A articulação se torna ainda mais perceptível ao olhar para a própria questão estatística, sempre convencendo da necessidade de cuidar e preservar, sob fulcro em "dados científicos". Henning (2019, p. 10) corrobora em relação aos elementos estatísticos e os prognósticos, reiterados pela ciência para reforçar comportamentos em relação ao meio: 
Descreve-se o já ocorrido, com saberes científicos e dados estatísticos. São eles que nos dizem o que aconteceu e porquê. Mas não é só isso: essa configuração permite auferir prognósticos, criar probabilidades plausíveis para se dizer, enfim, o que teremos a enfrentar, caso nossas ações individuais, coletivas e governamentais não se modifiquem. A partir do saber experto da ciência, auxiliada pela estatística, que descreve acontecimentos já vividos, temos um elemento importante que a ciência necessita debruçar seu olhar: o risco do colapso planetário.

Malette (2011, p. 14) ressalta que o próprio conceito de ambiente foi modelado pela questão estatística e com modos de operar as relações caóticas e aleatórias ocorridas no ambiente, em números controláveis e previsíveis através de ciências computacionais e modelos preditivos através da progressiva matematização da "natureza".

Outro embasamento que avigora essas práticas de um governo do planeta é em relação ao futuro. Foucault já provocava a pensar sobre como essa ideia de futuro reforça comportamentos, inclusive comenta no seu curso de 1978 "Segurança Território e População", que a cidade não é planejada para o presente de maneira estática, ela é pensada no futuro, no que pode acontecer:

[...] a cidade não vai ser concebida nem planejada em função de uma percepção estática que garantiria instantaneamente a perfeição da função, mas vai se abrir para um futuro não exatamente controlado nem controlável, não exatamente medido nem mensurável, e o bom planejamento da cidade vai ser precisamente: levar em conta o que pode acontecer (FOUCAULT, 2008c, p. 26).

Os Discursos Esverdeantes também trazem o futuro como elemento fundamental para reforçar os hábitos que os humanos devem ter no presente, visando o amanhã. Destacamos na Figura 2, uma sacola retornável "Seja consciente. Em uma sacola retornável cabe muita coisa, até mesmo a salvação do planeta" um suporte de papel higiênico em um banheiro de uma universidade, trazendo as mãos humanas no entorno de um planeta verde, informando: "Seja consciente! O futuro do planeta está em suas mãos", marca de batatas fritas que "você protege o meio ambiente para as futuras gerações" e uma etiqueta de roupa jeans “o futuro está em nossas mãos” salientando a responsabilidade com o meio ambiente, preservação de recursos naturais sendo essa uma "forma de abraçar o planeta e as gerações que estão por vir. Um novo caminho já começou a ser traçado - e você é a parte mais importante dele". 
Figura 2: Imagens ressaltando o futuro

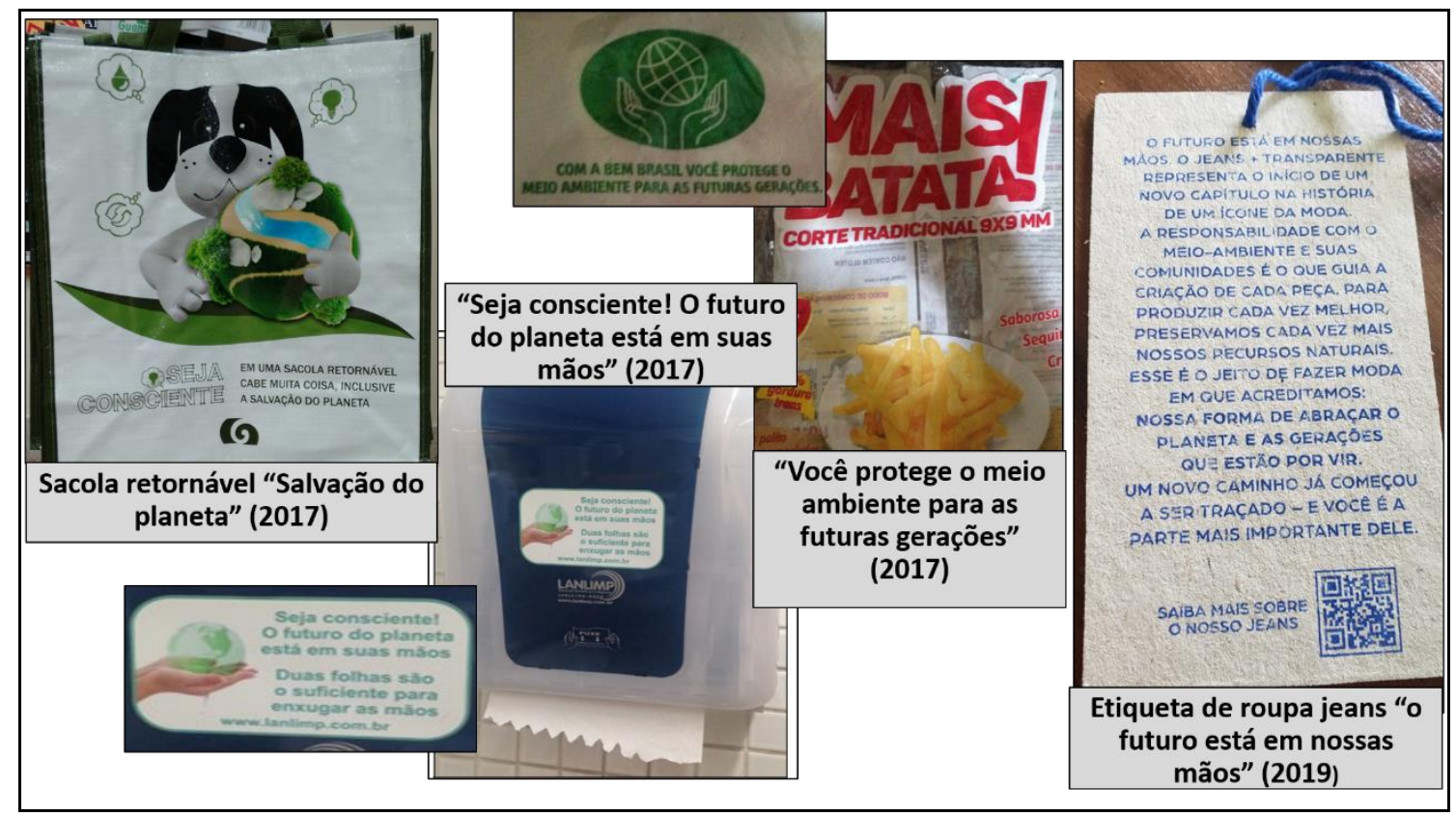

Fonte: Portfólio das imagens coletadas para a tese

As imagens do portfólio demonstram emblematicamente os atravessamentos ecopolíticos através da recorrência das imagens do planeta por diferentes mídias. Ao buscar entrelaçar a questão ambiental com os preceitos ecopolíticos, buscamos aporte aos elementos destacados por Rabinow e Rose (2006, p. 29) que atribuem destaque para constituições biopolíticas aos discursos de verdade, embasados por quem "pode" falar, ou seja, as autoridades competentes para falar tais verdades; as estratégias de intervenção sobre a coletividade e os modos de subjetivação em que os indivíduos são levados a atuar sobre si próprios, sob formas de autoridades e discursos de verdade que corroboram com tais comportamentos e ações.

Henning, entendendo a EA como um importante campo de saber que contribui para orientar, definir, apresentar modos de vida condizentes com o tempo em que vivemos, articula os três elementos de Rabinow e Rose: discursos de verdade, estratégias de intervenção e modos de subjetivação, para pensar a EA:

[...] a EA assume-se, com seus discursos de verdade, intervenções na vida cotidiana e subjetivações dos indivíduos como uma importante ferramenta bio/ecopolítica. No desejo de gerenciar ações verdes para o controle da vida, a EA vai conduzindo as condutas da massa de indivíduos, agindo nas ações cotidianas dos sujeitos. Chamo a atenção para o modo como vamos educando através do medo e do possível risco de perda planetária (HENNING, 2019, p. 378). 
Em se tratando de Educação Ambiental (EA), Barchi salienta sobre os riscos que são assumidos ao tomar a EA como solucionadora do planeta, como algo que desse conta de tudo, servindo de modulação de cidadãos modelo, ecologicamente ícones e instauradores de uma verdade, tendo como ator principal o "ecologista", um dócil indivíduo que participa dos movimentos sociais de defesa do meio ambiente, sem necessariamente o fazer contestar essa ecologia e esse ideal de EA (BARCHI, 2011, p. 11).

Os Discursos Esverdeantes ingressam na pauta do dia através de inúmeros lugares. Não precisamos procurar, o verde permeia a vida como um todo, além de permear, conduzem ações, orientam comportamentos, nos fazem compartilhar o dever de cuidar desse planeta.

Destacamos algumas imagens da Figura 3 que confluem para esse entendimento: uma sacola plástica que atesta "consciência ecológica: tem que usar. Sacola oxibiodegradável”, uma imagem de banheiro de hotel aonde diz que são gastos doze mil litros de água por mês para lavar as toalhas utilizadas uma vez, mas "você pode fazer a diferença" e pode "ajudar a preservar o planeta", o papel higiênico com a imagem de uma folha verde alerta para um consumo consciente e a toalha de banho traz em sua etiqueta "a toalha ecologicamente correta. Produzida dentro dos mais rigorosos processos para não agredir e não poluir o meio ambiente".

Figura 3: Imagens ressaltando discursos ambientais

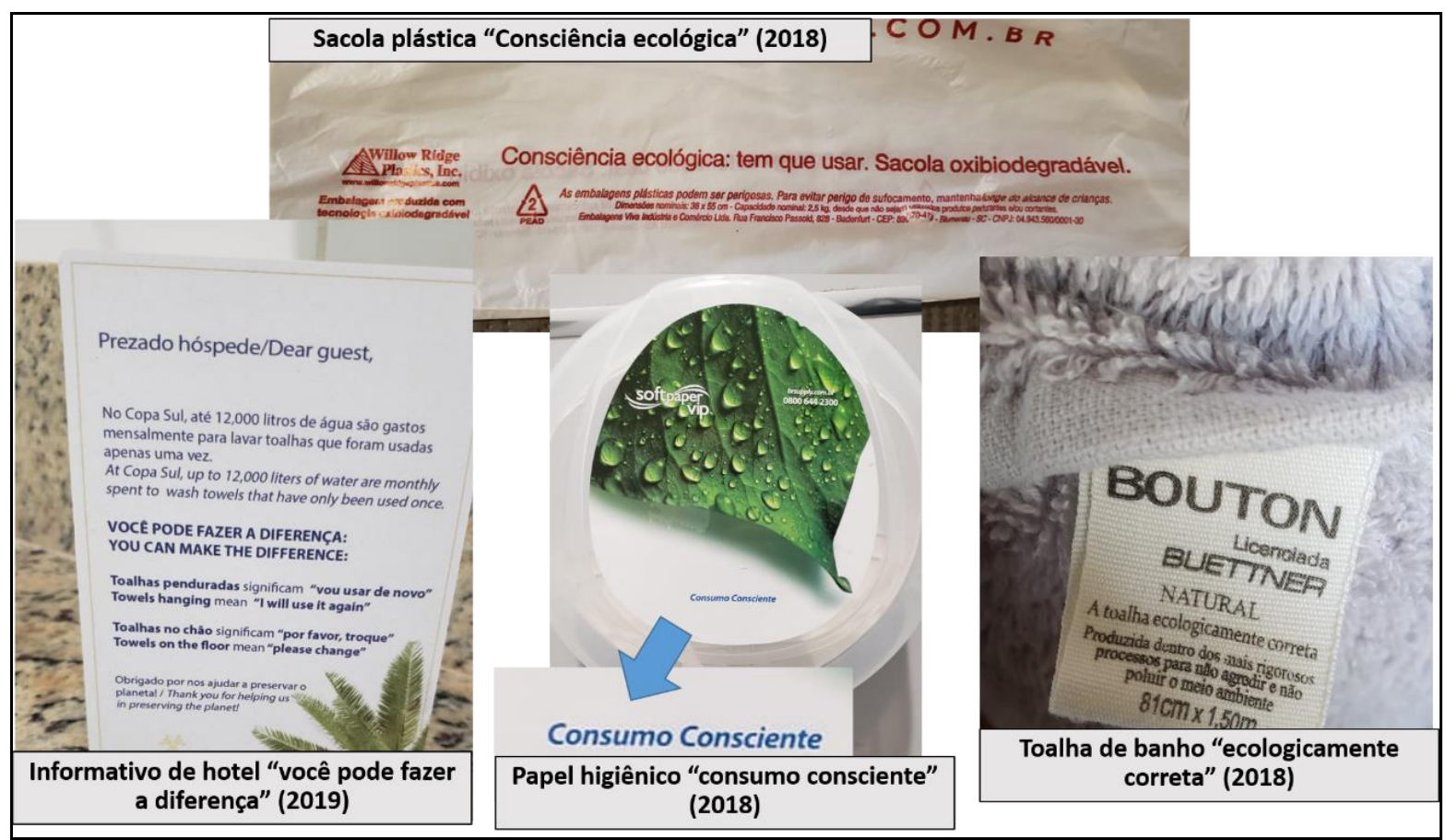

Fonte: Portfólio das imagens coletadas para a tese 
Trazemos algumas imagens do portfólio provindo de diferentes lugares. Entendemos que a população segue sendo alvo biopolítico, "mas agora o alvo é pluridimensionado pela convocação à participação na gestão do planeta, do Estado, de empresas, comunidades e na governamentalidade ambiental, assim, a biopolítica vai consolidando sua ultrapassagem pela ecopolítica" (PASSETI, 2013). As relações de poder não focam apenas na população, mas atuando em escala planetária, a ecopolítica passa a fazer parte das políticas da vida. Questões como desastres ambientais, perda da biodiversidade, mudanças climáticas são fenômenos que ameaçam inúmeras vidas, não apenas a humana e, em nome da vida e do planeta a ecopolítica vai gerindo as populações (AVILA e RIBEIRO, 2018, p. 98).

Sobre essa atualização das estratégias biopolíticas, Malette (2011, p. 21) analogicamente diz que: "o dragão está para trocar de pele", com a ampliação das noções de vida, população e economia, convergindo a um governo de "relações que ligam tudo e qualquer coisa, que apoia todos os seres vivos e não-vivos do mesmo modo, e que faz das fronteiras internas/externas uma questão secundária".

Com portfólio demonstrando a recorrência das imagens do planeta, tanto quanto enunciabilidade, quanto por visibilidade, o entendimento às práticas ecopolíticas são reforçadas, mas não apenas as imagens do planeta em si, as mãos humanas no entorno do globo chamam muito atenção, e essas imagens são muito recorrentes, o humano ocupando espaço de quem pode salvar, proteger e preservar o planeta para as presentes e futuras gerações e também ocupando o espaço daquele destruidor, desbravador e principal causador das mazelas ambientais. As imagens das mãos humanas, causam imensa inquietação, a presença humana é ínfima diante da idade planetária. São aproximadamente 3 milhões de anos, correspondendo a apenas alguns minutos na história geológica da vida (SEABRA, 2013, p. 17). Ainda assim é uma imagem bem recorrente, compartilhamos algumas na Figura 4: 
Figura 4: Imagens das mãos humanas em torno de práticas ambientais

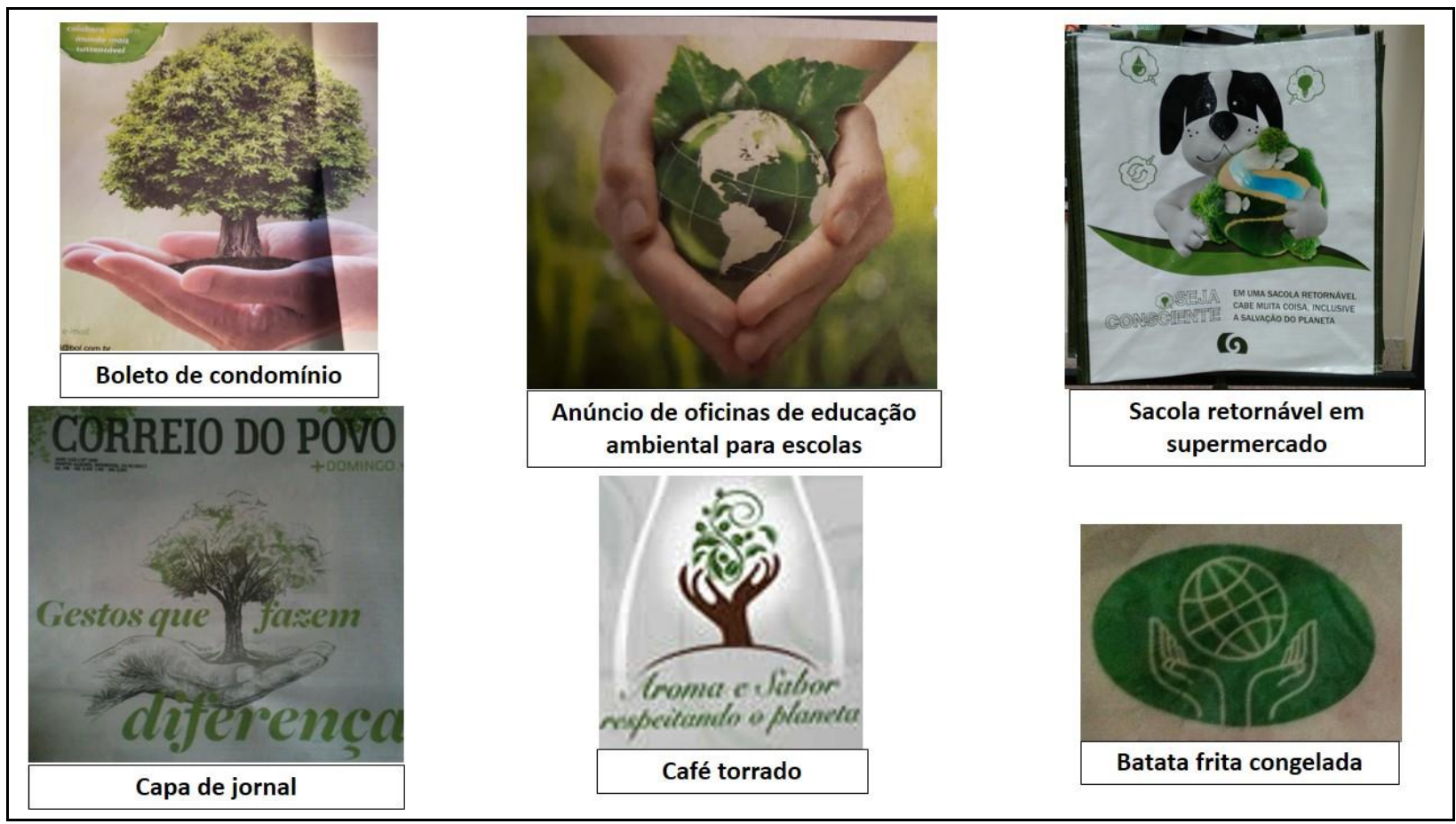

Fonte: Portfólio das imagens coletadas para a tese

As mãos humanas aparecem em diferentes mídias e, a partir da perspectiva teórica que assumimos na escrita do trabalho, entendemos essas imagens como potentes a pensar um cenário antropocêntrico, ou seja, o homem enquanto centro e/ou como algo que pensa fora do ambiente. Ou então como um heroico protagonista que ditará novos caminhos para enfrentar a crise ambiental como Carvalho (2001, p. 168) diz:

Um sujeito que pode ser visto em sua versão grandiosa como um sujeito heróico, vanguarda de um movimento histórico, herdeiro de tradições políticas de esquerda, mas protagonista de um novo paradigma políticoexistencial; em sua versão new age é visto como alternativo, integral, equilibrado, harmônico, planetário, holística; e também em sua versão ortodoxa, na qual é suposto aderir a um conjunto de crenças básicas, uma espécie de cartilha - ou ortodoxia - epistemológica e política da crise ambiental e dos caminhos para enfrentá-la.

Entendemos essa dúbia conotação humana ora de predador ora de salvador, como algo muito interessante para pensarmos a EA. Existe um planeta que, sob fulcro na ciência, está com sua capacidade de suporte saturada; principal causador é o homem; quem pode resolver é o homem; o mercado de consumo cresce e se expande utilizando as balizas verdes com forte apelo comercial e sob prática de incentivar a utilização de marcas, produtos e comportamentos ecologicamente adequados; verdades são dadas; 
comportamentos distribuídos nas prateleiras, sites, ruas, etiquetas, dentre outros. A água pode faltar! As geleiras estão derretendo! O planeta está com muito lixo! O medo, a crise estão aí! O homem torna-se um potente articulador e condutor de toda subjetividade que anima, orienta e move os Discursos Esverdeantes no cenário ecopolítico.

Nietzsche já dizia:

Cabe muito bem admirar o homem como um formidável gênio da construção, capaz de erguer sobre fundamentos instáveis e como que sobre a água corrente um domo de conceitos infinitamente complicado; por certo, a fim de manter-se firmemente em pé sobre tais fundamentos, cumpre ser uma construção como que feita com teias de aranha, suficientemente delicada que possa ser levada pelas ondas e firme o bastante para não ser despedaçada ao sopro do vento (NIETZSCHE, 2012, p. 39).

Sob inspiração em Nietzsche, pensamos a questão humana em relação ao planeta, muito reforçada em verdades erguidas, porém delicadas como teias de aranha que podem ser levadas pelas ondas, mas também são firmes que não despedaçam ao sopro de qualquer vento.

Entendemos que os atravessamentos ecopolíticos, que as verdades atribuídas às questões ambientais fazem parte do que somos hoje. Guimarães (2011) comenta sobre o que acontece:

Processos estes que não estão no horizonte de uma das configurações subjetivas mais atualizadas do contemporâneo. Essa que busca imprimir em nós, nos nossos desejos, nos nossos corpos, uma identidade "verde", ou seja, de um sujeito que interage "corretamente" com o planeta (sim, trata-se de uma identificação planetária e, portanto, nãolocalizada, não-regional, não-nacional, não-territorial, mas global). (grifos meus).

E esses comportamentos citados acima por Guimarães são esperados a todo momento, tocando em nossa maneira de agir, se comportar, falar e até mesmo viver perante ao que é distribuído. O Discurso Esverdeante está tão introjetado que os hábitos de ser e viver já são esperados. Já estamos tão acostumados que muitas vezes não contestamos essas "verdades".

Salientamos que na utilização de discursos, das imagens que falam por si, não se trata de analisar a veracidade de seus ditos, tampouco ousamos questionar a responsabilidade de rever certos hábitos de ser e agir. Mas o destaque que fazemos é em relação as práticas discursivas que estão permeando a contemporaneidade, como Foucault (2008, p. 133) esclarece:

Rev. Eletrônica Mestr. Educ. Ambient. Rio Grande. v. 37, n. 1. Seção especial: XI EDEA - Encontro e Diálogos com a Educação Ambiental. p. 228-246. jan/abr. 2020. 
Não podemos confundi-la com a operação expressiva pela qual um indivíduo formula uma idéia, um desejo, uma imagem; nem com a atividade racional que pode ser acionada em um sistema de inferência; nem com a "competência" de um sujeito falante, quando constrói frases gramaticais; é um conjunto de regras anônimas, históricas, sempre determinadas no tempo e no espaço, que definiram, em uma dada época e para uma determinada área social, econômica, geográfica ou linguística, as condições de exercício da função enunciativa.

Os exercícios enunciativos, se alocam em um conjunto de regras que imprimem em nossos modos de vida, verdades que fabricam nossos modos de ser e agir.

Com esse entendimento, cremos que ao trazer as imagens do planeta e o "eco" tão atrelados as questões ambientais, o conceito da Ecopolítica se mostra muito potente para pensarmos esses atravessamentos que, sob o signo verde, nos instiga a pensar, se comportar e agir de acordo com as que as mídias preceituam.

\section{Considerações não finais}

Assim como anunciado no início do texto, trata-se de um dos eixos de análise de uma tese que está em vias de ser finalizada. Através das imagens coletadas para a pesquisa, foi destacado o conceito de ecopolítica para pensarmos as estratégias biopolíticas também endereçadas às questões ambientais.

Não negamos a crise ambiental instalada, tampouco almejamos contestar a adoção de práticas mais benéficas ao planeta em que vivemos, mas acreditamos que o campo de saber ambiental tenha sido muito impulsionado, fabricado e construído a partir dos discursos da crise, com articulação à constante distribuição de discursos de verdade que nos mostram, ensinam e educam como devemos proceder, o que precisamos fazer e pouco questionamos. Esses atravessamentos são impulsionados por diferentes mídias que além de veiculador também produzem saberes, ao comunicar, vão produzindo sujeitos, interpelando no preenchimento de subjetividades que nos constituem a todo momento.

Buscamos estimular que se pense em relação aos enunciados que nos fazem ver e sermos quem somos na contemporaneidade: sujeitos tão marcados pelas condutas eco, por um esverdeamento discursivo que nos aloca em papel de causador dos problemas ambientais e também como possível salvador do planeta, dentre tantos outros atravessamentos que nos conduzem rebanhamente em prol de um compartilhar de responsabilidades e, que também, nos "conforta" pois, mesmo que o planeta esteja em 
crise, podemos seguir consumindo pois há uma gama infindável de produtos e/ou serviços que afirmam convergir nessa preocupação com o planeta.

Acreditamos que a potência da Educação Ambiental é o quanto podemos contribuir para problematizar esses tantos discursos que a vida nos traz; pensar a EA como reconexão do mundo, conosco, não uma preocupação aterrorizante, amedrontadora de que o mundo vai acabar caso não nos comportemos conforme os meios de comunicação preceituam, mas uma relação de articulação com o ser humano e a própria natureza. Articulação mesmo, pois a separação já foi dada pela modernidade.

O convite é para que possamos tentar criar fissuras e arestas, que mesmo sendo pequenas possam nos fazer pensar em nossas maneiras de ser e agir.

Entendemos que nesses movimentos de movimentar o pensamento, possam incidir tensionamentos em relação a domínios tão consolidados. Sacudindo o que chega com tanta legitimidade e certeza é a potência de resistir e aí que está parte da motivação de escrever um trabalho em um evento de Educação Ambiental. E, assim colocamos um ponto, não um ponto final, mas reticências para que a prosa possa prosseguir para além dessas páginas:

\section{O desejo é que os fios tecidos na composição desse exercício de escrita, possibilitem} subversivos movimentos ao ato de pensar sobre os atravessamentos que interpelam o caminhar...

\section{Referências}

AVILA, Dárcia Amaro.; RIBEIRO, Paula Regina Costa. Notas sobre a sustentabilidade em programas ambientais globais. In: HENNING, Paula Correa; MUTZ, Andresa Silva da Costa; VIEIRA, Virgínia Tavares. Educações Ambientais Possíveis: Ecos de Michel Foucault para pensar o presente. Curitiba: Appris, 2018. p. 85-97.

BARCHI, Rodrigo. Educação e Meio Ambiente Entre a Biopolítica e a Biopotência. Revista de Estudos Culturais, Sorocaba-SP, v. 37, p. 167-179, jun 2011.

CARVALHO, Isabel Cristina De Moura. A invenção do Sujeito Ecológico: Sentidos e Trajetórias em Educação Ambiental. Tese de doutorado Programa de Educação da Faculdade de Educação da Universidade Federal do Rio Grande do Sul. [S.1.]. 2001.

CASTRO, Edgardo. Vocabulário de Foucault: um percurso pelos seus temas conceitos e autores. 2. ed. Belo Horizonte : Autêntica, 2016. 
FOUCAULT, Michel. O Sujeito e o Poder. In: DREYFUS, H.; RABINOW, P. Michel Foucault: uma trajetória filosófica para além do estruturalismo e da hermenêutica. Rio de Janeiro: Forense Universitária, 1995. p. 231-249.

FOUCAULT, Michel. Ditos e Escritos IV - Estratégia, Poder-Saber. Rio de Janeiro: Forense Universitária, 2006.

FOUCAULT, Michel. A arqueologia do saber. Rio de Janeiro: Forense Universitária , 2008.

FOUCAULT, Michel. Segurança, território e população. São Paulo: Martins Fontes, 2008c.

FOUCAUlT, Michel. Microfísica do Poder. 3a. ed. Rio de Janeiro: Paz e Terra, 2015.

GUIMARÃES, Leandro Belinaso. Notas sobre o dispositivo da sustentabilidade e a formação de sujeitos "verdes". Anais do $4^{\circ}$ SBECE, ULBRA. Canoas: [s.n.]. 2011. p. 1 14.

HENNING, Paula. Estratégias Bio/Ecopolíticas na Educação Ambiental: a mídia e o aquecimento global. Educação Unisinos, v. 23, n. 2, p. 367-382, abril-junho 2019.

HENNING, Paula. Resistir ao presente: tensionando heranças modernas para pensar a Educação Ambiental. Ciência e Educação, Bauru, v. 25, p. 763-781, setembro 2019.

HENNING, Paula Corrêa; SILVA, Gisele. Ruiz. Rastros da Educação Ambiental. O dissenso como potência criadora. In: HENNING, Paula Correa; MUTZ, Andresa Silva da Costa; VIEIRA, Virgínia Tavares. Educações Ambientais Possíveis: Ecos de Michel Foucault para pensar o presente. Curitiba: Appris, 2018. p. 151-162.

MALETTE, Sébastien. Foucault para o próximo século: ecogovernamentalidade. ecopolítca, São Paulo, p. 4-25, 2011.

NIETZSCHE, Friedrich. Sobre verdade e mentira. São Paulo: Hedra, 2012.

PASSETI, Edson. Transformações da biopolítica e emergência da ecopolítica. Ecopolítica, São Paulo, p. 2-37, jan-abr 2013.

RABINOW, Paul.; ROSE, Nikolas. O conceito de biopoder hoje. Política \& trabalho, p. 27-57, abril 2006.

SAUQUILLO, Julián. Michel Foucault: Poder, saber y subjetivación. Madri: Alianza editorial, 2017.

SEABRA, Giovanni. Educação Ambiental: conceitos e aplicações. João Pessoa: UFBP, 2013.

VEIGA-NETO, Alfredo. Ecopolítica: um novo horizonte para a Biopolítica. REMEA Revista Eletrônica do Mestrado em Educação Ambiental, p. 208-224, 2014. 
Submetido em: 01-03-2020.

Publicado em: 17-04-2020.

Rev. Eletrônica Mestr. Educ. Ambient. Rio Grande. v. 37, n. 1. Seção especial: XI EDEA - Encontro e Diálogos com a Educação Ambiental. p. 228-246. jan/abr. 2020.

E-ISSN 1517-1256 